\title{
FRACTURE CHARACTERIZATION FOR CARBONATE RESERVOIRS: A CASE STUDY ON NT OILFIELD IN THE EASTERN MARGIN OF THE PRE-CASPIAN BASIN
}

\author{
WANG, S.-Q. - ZHAO, L.* - LUO, M. - ZHAO, W.-Q. - LI, J.-X. - WANG, C.-G. -SUN, M. - \\ ZHAO, L.-D. - LI, W.-Q. - LI, C.-H. \\ PetroChina Research Institute of Petroleum Exploration and Development \\ 20\#, Xueyuan Road, Haidian District, 100083 Beijing, China \\ (phone: +86-10-8359-3284; fax: +86-10-8359-8636) \\ *Corresponding author \\ e-mail: zhaolun@petrochina.com.cn; phone: +86-10-8359-8489; fax:+86-10-8359-8636
}

(Received $17^{\text {th }}$ Jan 2018; accepted $9^{\text {th }}$ May 2018)

\begin{abstract}
In order to make full use of well logging information to accurately predict the fracture distribution of carbonate reservoir, we use several log curves to comprehensively identify and delineate the structural fractures, dissolved fractures and sutured fractures of different occurrences, scales and geneses in the North Truwa oilfield of the Pre-Caspian Basin in Kazakhstan. The resistivity differenceratio method may be used to identify high-angle fractures. The 3-porosity ratio method, which tends to be affected by dissolved pores and vugs, is applicable to low-angle fractures and microfractures. By using each single method separately, only $54.8 \%$ of fractures on the average may be identified. The comprehensive probability density method which integrates the above two methods improves the accuracy of fracture identification to $73.6 \%$ as per the validation of core and imaging logging data. Fracture distribution in the study area is dominated by sedimentation, structure and diagenesis. In the lateral direction, the structural highs and areas with intense karstification may demonstrate high fracture probability density and thus areinterpreted to be rich in structural and dissolved fractures. In the vertical direction, more fractures may occur in the brittle intervals with small shale and gypsum contents. The results of fracture prediction are consistent with the sedimentary diagenesis of carbonate reservoirs, indicating that the method is feasible to predict the fracture.
\end{abstract}

Keywords: fracture classification, fracture signatures, fracture prediction, conventional logging, comprehensive probability density, distribution

\section{Introduction}

It is challenging to characterize the fractures in carbonate formations. Carbonate fractures may be delineated in the perspective of genesis and geometry by using seismic, logging and stress data (Lai et al., 2017; Ameen et al., 2012; Kazatchenko et al., 2007). In a field with a number of wells drilled, fracture characterization tends to be accomplished by using logging methods, such as the method of Wavelet Transform (Dong et al., 2013) which obtain the high-frequency weak signal of fracture in logs by means of wavelet decomposition and reconstruction, Matrix index method (Sun et al., 1999) which identify the fracture by calculating the acoustic skeleton index and the density skeleton index and constructing the rendezvous skeleton index, 3-porosity ratio (Gong et al., 2007; Luo et al., 2001) which characterize fracture development by density, neutron and acoustic plot, fractal dimension method (Tang et al., 2012) which determine the fractal dimension that reflects the complexity of fracture reservoir by multiple mesh encryption, and resistivity difference-ratio (Yan et al., 2009; Cai et al., 2003) which characterize fracture development by the difference ratio of deep and shallow resistivities. But the accuracy of the methods is related to fracture geometry, 
occurrence and scale, especially when only a single method is used to identify multigeometry multi-occurrence fractures of complex origins. A solution is comprehensive identification by using a combination of various log curves. We make a case study on the North Truwa oilfield at the east margin of the Pre-Caspian Basin in Kazakhstan. The objective is to improve fracture characterization by analyzing fracture signatures and the capability of existing methods and finding improved methods with conventional log curves.

\section{Materials}

\section{Geological setting}

The North Truwa oilfield tectonically lies in the eastern slope of the ZharkamysEnbek palaeohigh at the east margin of the Pre-Caspian Basin in Kazakhstan. It is a faulted anticlinal structure whichextends in the NE direction and is bounded by a NEstrike boundary fault on the east (Fig. 1). A package of thick carbonate rocks were deposited in the Paleozoic Carboniferous Period (He et al., 2014; Zhao et al., 2013; Zhao et al., 2010; Bian et al., 2011; Zheng et al., 2005). KT-I in the Middle and Upper Carboniferous Series is the major hydrocarbon bearing formation and is vertically subdivided into three oil layers, i.e. A, Б and B. During KT-I deposition, the open platform in southeastern deep water changed into restricted platform and evaporate platform in shallow water toward the northwest.

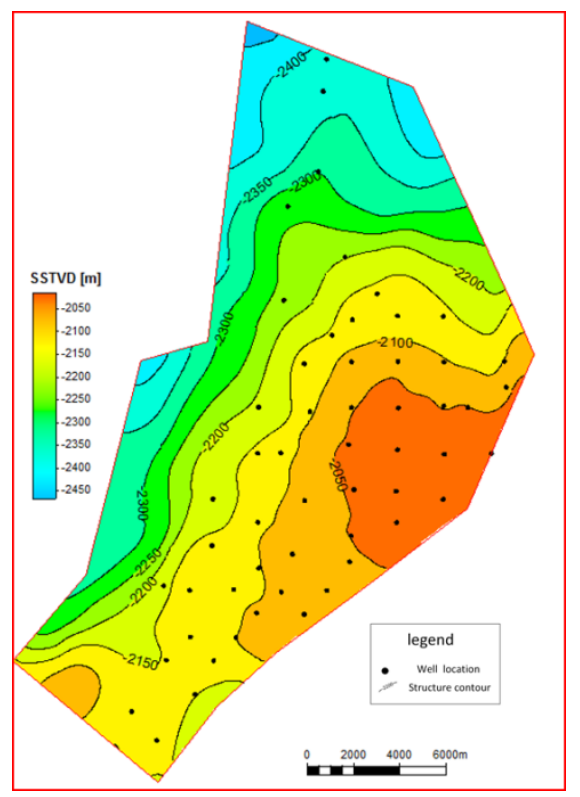

Figure 1. Location and structure map of the study area. (SSTVD: subsea true vertical depth)

Due to the elevation of the whole area before Permian deposition, the layer A at the top experienced differential denudation and early deposited carbonate rocks were exposed to the leaching process of atmospheric water (Wang et al., 2012). Lithologies vary with sedimentary environment and change from grainstone in the open platform to dolomitic limestone and limy dolostone to dolostone, gypseous dolostone and gypsum rocks in the evaporate platform (Fig. 2). Vertically B3-B5 in the lower section deposited 
in deep water at the early stage of KT-I deposition has a high shale content of $19.9 \%$ on the average, dolomite content of $10.7 \%$ and average calcite content of $69.4 \%$. Б1-B2 is composed of relatively clean limestone and dolomitic limestone with small shale content of $7.0 \%$ on the average and increased dolomite content of $10.6 \%$ and calcite content of $82.3 \%$. A2-A3 in the upper section has an increased average shale content of $15.7 \%$ as well as increased average dolomite content of $24.0 \%$, average anhydrite content of $5 \%$, and average calcite content of $55.4 \%$ in the evaporate platform.

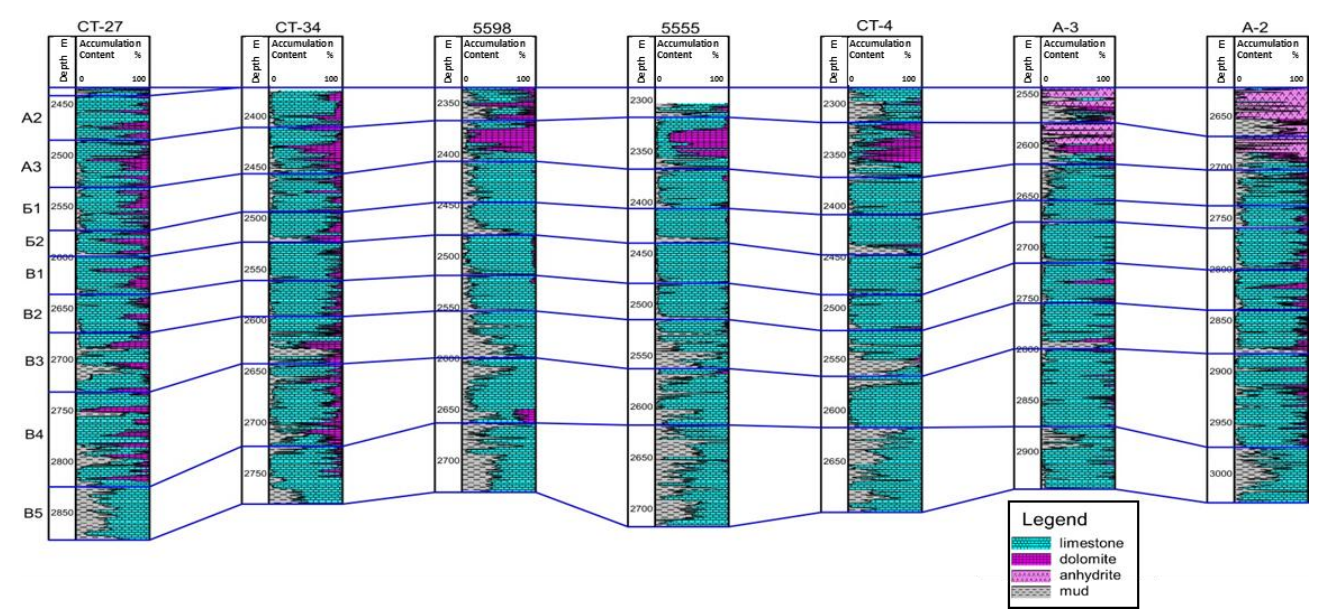

Figure 2. Lithologic section of the study area

\section{Fractures}

As per fracture geneses, three types of fractures, i.e. structural fracture, dissolved fracture and sutured fracture, could be observed on cores and image logs. Large fractures could be visually inspected and microfractures of which the apertures are generally less than $0.1 \mathrm{~mm}$ (Anders et al., 2014; Lai et al., 2017) may only be examined by using a microscope. Fracture dip ranges from $10^{\circ}$ to $90^{\circ}$ and there are also irregular fractures. Most fractures in the oil field are open seams, and only few are filled with calcite.

\section{Structural fractures}

Structural fractures are common in the study area due to the effect of tectonic stress. Fracture surface is flat or distributes in en-echelon (Fig. 3a). Two groups of fractures with different occurrences may co-exist (Fig. 3b). These fractures vary greatly from large fractures which could be identified on seismic sections to small fractures which could be identified on cores and imaging log curves to microfractures which may only be observed by using a microscope (Fig. 3c). Fracture dip Angle is widely distributed from $10^{\circ}$ to $90^{\circ}$ (Fig. 3d).

\section{Dissolved fractures}

Dissolved fractures surface is irregular and fracture width is in the range of 0.1$5 \mathrm{~mm}$. Both large fractures and microfractures could be inspected (Fig. 3e, f). Generally there are no oriented fractures. Some oriented fractures are early structural fractures 
corroded and enlarged by acidic fluids at the late stage (Fig. $3 g$ ). Fluids usually flowed through fractures; thus dissolved fractures are often associated with structural fractures.

\section{Sutured fractures}

According to the core observation, most sutured fractures are opened and filled with crude oil; this means the existence of sutured fractures is important to oil accumulation and flow. Sutured fractures exhibit various occurrences, including intra-stratal lowangle sutured fractures, vertical sutured fractures and high-angle oblique sutured fractures. A single or a group of sutured fractures may be examined (Fig. 3h). Dissolved fractures may also occur together with sutured fractures (Fig. 3i) because of fluid flow through sutured fractures.

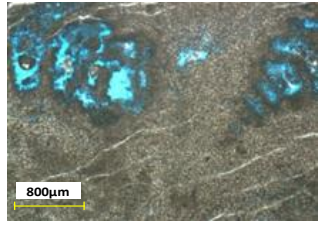

$\mathbf{a}$

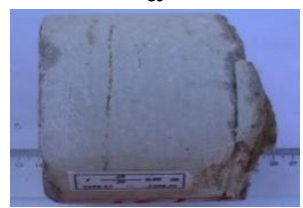

d

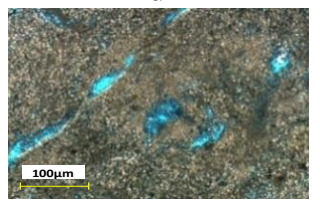

g

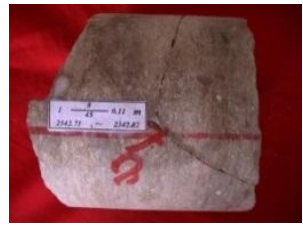

b

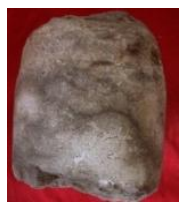

e

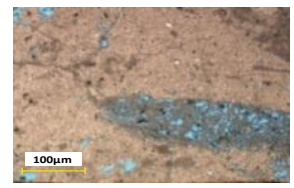

h

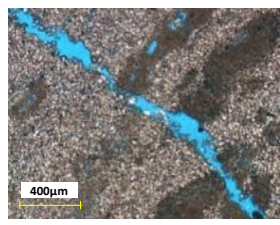

c

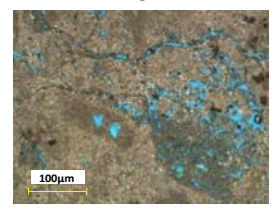

f

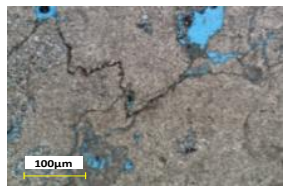

i

Figure 3. Fractures in the study area. $\boldsymbol{a}$. En-echelon structural fractures. $\boldsymbol{b}$. Structural fractures with two occurrences. $\boldsymbol{c}$. Microstructural fractures observed under a microscope. d. Low-angle structural fractures. $\boldsymbol{e}$. Macro dissolved fractures. $f$. Micro dissolved fractures. $g$. Early structural fractures corroded and enlarged. $\boldsymbol{h}$. Net-shaped sutured fractures. $\boldsymbol{i}$. Corroded sutured fractures

There are seldom fractures with single genesis, single occurrence or single scale separately occurring in the area. Fractures with various geneses and occurrences usually exist together with varying degrees of development. In this circumstance, it is hard to identify single-genesis or single-scale fractures by using conventional log curves. But it is possible and significant to quantitatively predict fractures in an interval.

\section{Methods}

We used some published techniques, i.e. resistivity difference-ratio and 3-porosity ratio, based on conventional $\log s$ to identify fractures in the North Truwa oilfield and validated the results with core and imaging log data. Both techniques were demonstrated to be of low credibility. In view of the complexity of fracture geneses and 
occurrences, two techniques were combined to identify multi-genesis multi-occurrence fractures in carbonate rocks.

\section{Resistivity difference-ratio}

The resistivity close to and far away from the wellbore will be measured by deep and shallow resistivity logging. The resistivity around the wellbore will decrease if the mud in the wellbore flows into the formations through fractures (Babadagli and Al-Salmi, 2004). For high-angle fractures (above $75^{\circ}$ ), both deep and shallow resistivity curves exhibit remarkable decrease, especially the shallow resistivity due to more impact of mud invasion on near-hole area. Consequently there is a positive difference between deep and shallow resistivity (Sibbit and Faivre, 1985) (Fig. 4a). The magnitude is much higher than that caused by the existence of pores. For low-angle fractures (below $30^{\circ}$ ) or horizontal fractures, the mud may flowperpendicularly to the wellbore into the fractures far away from the wellbore; thus deep resistivity exhibits larger decrease than shallow resistivity because various fluids (oil, gas, water or mud) in the fractures have much lower resistivity than tight rocks. This negative difference reaches a maximum at the interval with horizontal fractures (Sima, 2009) (Fig. 4b). Owing to the impact of fluids and filling materials in fractures, positive difference or zero difference may also occur in addition to negative difference at the interval with low-angle fractures.

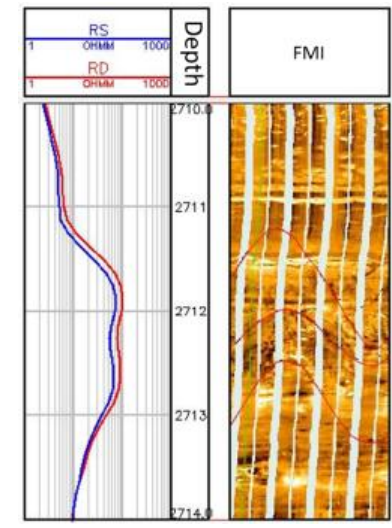

a

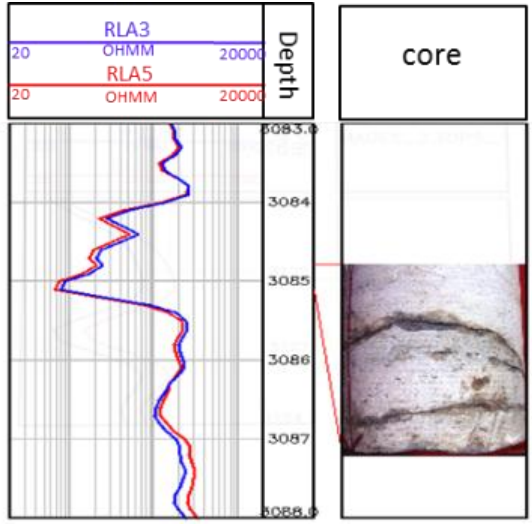

b

Figure 4. Fractures and corresponding resistivity responses

Inaccordance with resistivity responses to fractures, the method of resistivity difference-ratio was widely applied to fracture identification and prediction (Sun et al., 1999; Dond et al., 2013) by using the equation $R T C=\left(R_{t}-R_{l l s}\right) / R_{l l s}$, where RTC is deep-shallow resistivity difference ratio, $R_{l l s}$ is the shallow resistivity, $R_{t}$ is the true resistivity after invasion correction by $R_{t}=2.589 R_{l l d}-1.589 R_{l l s}$, and $R_{l l d}$ is the deep resistivity.

In view of the uncertainty of resistivity difference for low-angle fractures, we substitute the deep resistivity with true resistivity to calculate the difference for fracture and pore discrimination. Generally at the interval with fractured hydrocarbon reservoirs, $\mathrm{R}_{\mathrm{t}}>\mathrm{R}_{\mathrm{lls}}$ and $\mathrm{RTC}>0$; RTC shows positive anomalies higher than the base line. At the fractured interval with water or tight interval, $\mathrm{R}_{\mathrm{t}} \approx \mathrm{R}_{11 \mathrm{~s}}$ and $\mathrm{RTC} \approx 0$. 


\section{Three-porosity ratio}

Acoustic log curve also demonstrates some responses to the existence of fractures because of acoustic attenuation by fractures. At the fractured interval, later arrivals instead of the head wave will be recorded; thus the log curve exhibits increased acoustic time or cycle skip. This leads to large acoustic porosity. At the interval with high-angle fractures, there are no distinct responses on the curve because acoustic waves bypass the fractures as per the principle of least distance. At the interval with oblique, horizontal or net-shaped fractures, the log curve exhibits slightly jagged profile due to increased acoustic time or cycle skip caused by severe acoustic attenuation (He et al., 2014; Bian et al., 2011) (Fig. 5). Therefore the variations in acoustic porosity somewhat indicate the existence of fractures, especially horizontal, net-shaped and micro fractures (Sima et al., 2009; Wang et al., 2006). Acoustic wave is compressional wave and thus more sensitive to matrix pores uniformly distributing in the rock and less sensitive to secondary dissolved pores irregularly appearing in the rock. In such a circumstance, the increment of acoustic porosity is small (Li et al., 2013).

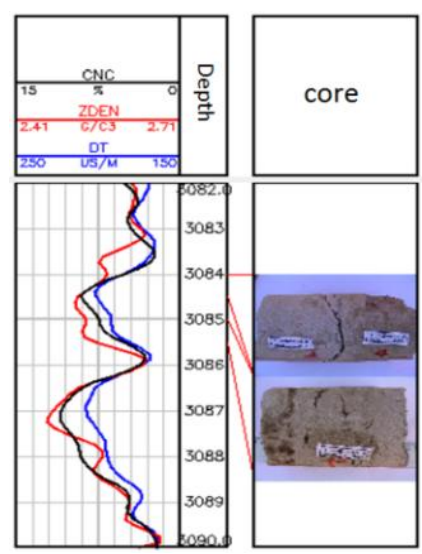

Figure 5. Responses of porosity logs to fractures

Neutron porosity and density porosity indicate the total porosity of matrix pores, secondary dissolved pores and fractures. The existence of fractures and secondary dissolved pores may lead to larger increments of neutron porosity and density porosity than that of acoustic porosity. In other words, the gap between total porosity (neutron porosity and density porosity) and acoustic porosity will increase at the interval with secondary dissolved pores and fractures.

The porosity difference-ratio, RP, is used for fracture characterization and defined as the function of neutron porosity $\Phi_{N}$, density porosity $\Phi_{D}$, acoustic porosity $\Phi_{S}$ and total porosity $\Phi_{T}$, as shown by (Eqs. 1 and 2).

$$
\begin{gathered}
\Phi_{T}=\sqrt{\frac{\Phi_{D}^{2}+\Phi_{N}^{2}}{2}} \\
R_{p}=\frac{\left|\Phi_{T}-\Phi_{S}\right|}{\Phi_{T}}
\end{gathered}
$$


When RP > 0, the development of secondary reservoir space such as fracture is indicated. A large RP indicates more secondary pore space including fractures, dissolved pores and microfractures.

\section{Comprehensive probability density}

The area has more low-angle fractures than high-angle fractures, so the resistivity difference-ratio method is inferior to 3-porosity ratio method in fracture identification. For both methods, only $55 \%$ of fractures could be identified on the average. It is hard to identify the fractures with multi-genesis, multi-scale and multi-occurrence by using a single method. Thus two methods were combined to determine the comprehensive probability density of fracture. The procedure is described as follows.

Step 1 (Eqs. 3 and 4): calculate the normal or nearly normal distribution of resistivity (Yan et al., 2009) because of the original skewed distribution (non-uniform numerical distribution).

$$
\begin{aligned}
\mathrm{RTC}^{\prime} & =\ln (\mathrm{RTC}+1) \\
\mathrm{RP}^{\prime} & =\ln (\mathrm{RP}+1)
\end{aligned}
$$

Step 2 (Eqs. 5, 6, 7 and 8): normalize RTC derived from the resistivity differenceratio method and RP derived from the 3-porosity ratio method, and then calculate corresponding probability density for fracture characterization.

$$
\begin{gathered}
\mathrm{RTC}^{\prime} \geq 0: \mathrm{P}_{\mathrm{RTC}}=1-\exp \left(-\mathrm{RTC}^{\prime}\right) \\
\mathrm{RTC}^{\prime} \leq 0: \mathrm{P}_{\mathrm{RTC}}=0 \\
\mathrm{RP}^{\prime} \geq 0: \mathrm{P}_{\mathrm{RP}}=1-\exp \left(-\mathrm{RP}^{\prime}\right) \\
\mathrm{RP}^{\prime} \leq 0: \mathrm{P}_{\mathrm{RP}}=0
\end{gathered}
$$

Step 3 (Eqs. 9 and 10): validate the results and feasibility for reservoir characterization by using core and imaging log data. The thickness of the fractured interval was calculated based on above two methods and core and imaging log data. The percentage of accuracy was then used as the weighting factor for each method.

$$
\begin{aligned}
\mathrm{X}_{\mathrm{RTC}} & =\mathrm{H}_{\mathrm{RTC}} / \mathrm{H} \\
\mathrm{X}_{\mathrm{RP}} & =\mathrm{H}_{\mathrm{RP}} / \mathrm{H}
\end{aligned}
$$

Here, $\mathrm{H}_{\mathrm{RTC}}, \mathrm{H}_{\mathrm{RP}}$ and $\mathrm{H}$ represent the thickness of the fractured interval calculated by above two methods and core or imaging log data, respectively (Eqs. 11 and 12).

$$
\mathrm{W}_{\mathrm{RTC}}=\mathrm{X}_{\mathrm{RTC}} /\left(\mathrm{X}_{\mathrm{RTC}}+\mathrm{X}_{\mathrm{RP}}\right)
$$




$$
\mathrm{W}_{\mathrm{RP}}=\mathrm{X}_{\mathrm{RP}} /\left(\mathrm{X}_{\mathrm{RTC}}+\mathrm{X}_{\mathrm{RP}}\right)
$$

Here, $\mathrm{W}_{\mathrm{RTC}}$ and $\mathrm{W}_{\mathrm{RP}}$ represent the weighting factor for each method, respectively.

Step 4 (Eqs. 13): calculate the comprehensive probability density.

$$
\mathrm{P}=\mathrm{W}_{\mathrm{RTC}} \times \mathrm{P}_{\mathrm{RTC}}+\mathrm{W}_{\mathrm{RP}} \times \mathrm{P}_{\mathrm{RP}}
$$

\section{Results}

As per the validation by core and image logs data from 5 wells, RTC results are more sensitive to high-angle fractures and less sensitive to low-angle and horizontal fractures; $82 \%$ of high-angle fractures on the average were identified and only $26 \%$ of low-angle fractures were identified. Due to the complexity of fracture occurrence, on the whole, $31.9-74.1 \%$ of fractures, with an average of $49.5 \%$, were identified in the study area. As shown in Figure 6a, Well UT-1 was examined to have high-angle fractures at 2707$2714 \mathrm{~m}$ and the average dip angle is $70.6^{\circ}$. The fractured interval was interpreted to be $1.8 \mathrm{~m}$ thick on the imaging log curve, which is reconciled with the thickness of $2 \mathrm{~m}$ in terms of high positive RTCs. As shown in Figure 6b, Well CT-20 was observed to have nearly horizontal fractures at 3164.4-3165.1 $\mathrm{m}$ and 3167.5-3168.1 $\mathrm{m}$. The fractured intervals were interpreted to be 0.7 and $0.6 \mathrm{~m}$ thick, respectively. But on the RTC profile, the upper interval with apparent positive anomalies was interpreted to be a fractured interval of $0.6 \mathrm{~m}$ thick, whereas the lower interval with no distinct anomalies was interpreted to have $0 \mathrm{~m}$ fractured interval. This means only $46.2 \%$ of fractured intervals were identified.
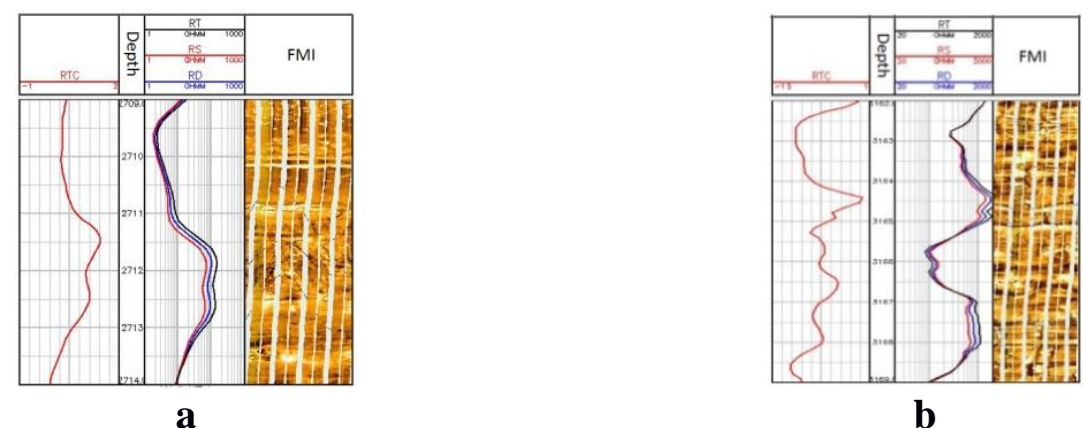

Figure 6. RTC-based fracture identification

The Three-porosity ratio result was validated by core and imaging log data to be of limited accuracy. For example, the existence of low-angle fractures at 3101-3104 $\mathrm{m}$ in Well CT-20 is in agreement with high RP (Fig. 7a) and microfractures at 3213.47$3213.53 \mathrm{~m}$ in Well CT-4 is in agreement with the average RP of 5.7 (Fig. 7b). The interval at 2600-2601 $\mathrm{m}$ in Well CT-10 with no fractures but with secondary dissolved pores also exhibits high RP (Fig. 7c), whereas the interval at 2711-2712 $\mathrm{m}$ in Well UT-I with abundant high-angle fractures does not illustrate significant RP variations (Fig. 7d). This means that the method is applicable to the identification of low-angle fractures and microfractures. The results are not affected by the existence of water layers but tend to be affected by secondary dissolved pores. In addition, high-angle 
fractures cannot be identified accurately. As per the statistics of 5 wells, 48-72.5\%, with an average of $61.5 \%$, of fractures could be identified.

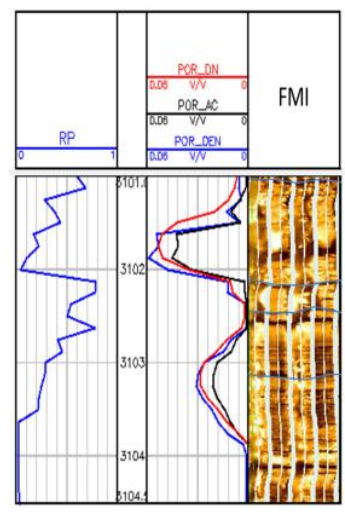

a

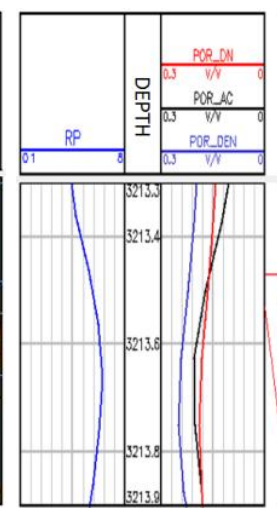

b

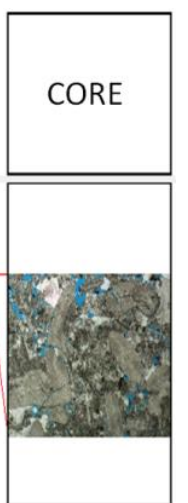

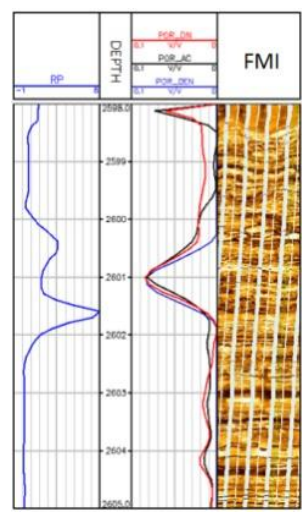

c

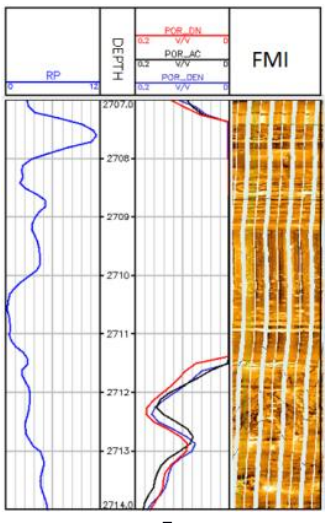

d

Figure 7. Fracture identification by 3-porosity ratio method

According to core and image logs, the $\mathrm{P}$ value of fracture development period is generally greater than $20 \%$. Therefore, the position of $20 \%$ above the baseline of $\mathrm{P}$ value is used as the lower limit of fracture development, and the further the deviation from the baseline, the higher the degree of fracture development. Five cored wells were included in the calculation. The weighting factor for the resistivity difference-ratio method was estimated to be $0.395-0.531$ with an average of 0.44 ; the factor for the 3 porosity ratio method was estimated to be $0.469-0.635$ with an average of 0.56 (Table 1).

Table 1. Parameters for the comprehensiveprobability density method

\begin{tabular}{|c|c|c|c|c|c|c|c|c|c|c|}
\hline Type & $\begin{array}{c}\text { Well } \\
\text { no. }\end{array}$ & $\begin{array}{c}\text { Thickness } \\
\text { of cored } \\
\text { interval by } \\
\text { core } \\
\text { observation } \\
\text { (m) }\end{array}$ & $\begin{array}{l}\text { Thickness } \\
\text { of cored } \\
\text { interval } \\
\text { by RTC } \\
\text { method } \\
(\mathrm{m})\end{array}$ & $\begin{array}{l}\text { Thickness } \\
\text { of cored } \\
\text { interval } \\
\text { by RP } \\
\text { method } \\
\text { (m) }\end{array}$ & $\mathbf{X}_{R T C}$ & $\mathbf{X}_{R P}$ & $W_{R T C}$ & $\mathbf{W}_{R P}$ & $\begin{array}{c}\text { Thickness of } \\
\text { cored interval } \\
\text { by P } \\
\text { interpretation } \\
\text { (m) }\end{array}$ & $\begin{array}{c}\text { Percentage } \\
\text { of } P \\
\text { accuracy }\end{array}$ \\
\hline \multirow{6}{*}{$\begin{array}{c}\text { Parametric } \\
\text { calculation well }\end{array}$} & CT4 & 63.5 & 34.5 & 30.5 & 0.544 & 0.48 & 0.531 & 0.469 & 47.685 & $75.09 \%$ \\
\hline & CT10 & 32.9 & 10.5 & 19.3 & 0.319 & 0.555 & 0.365 & 0.635 & 22.376 & $68.01 \%$ \\
\hline & CT22 & 70 & 51.9 & 50.8 & 0.741 & 0.725 & 0.506 & 0.494 & 50.943 & $72.78 \%$ \\
\hline & CT41 & 34.2 & 14.2 & 20.9 & 0.415 & 0.612 & 0.404 & 0.596 & 28.1288 & $77.40 \%$ \\
\hline & 5555 & 40.5 & 18.5 & 28.4 & 0.457 & 0.701 & 0.395 & 0.605 & 29.646 & $73.20 \%$ \\
\hline & Avg. & 48.2 & 25.9 & 30.0 & 0.495 & 0.615 & 0.4402 & 0.5598 & 35.75576 & $73.30 \%$ \\
\hline Verified well & 5598 & 12.6 & 5.3 & 7.2 & 0.424 & 0.568 & & & 9.475 & $75.20 \%$ \\
\hline
\end{tabular}

The average weighting factors were then used to calculate the comprehensive probability density, P. For these 5 cored wells, the percentage of accuracy $\left(\mathrm{X}_{\mathrm{RTC}}\right)$ for the resistivity difference-ratio method was $31.9-74.1 \%$ with an average of $49.5 \%$ and the accuracy $\left(\mathrm{X}_{\mathrm{RP}}\right)$ for the 3-porosity ratio method was $48-72.5 \%$ with an average of $61.5 \%$. The accuracy for the comprehensive method was $68.01-77.4 \%$ with the increase by $23.8 \%$ and $11.8 \%$, respectively, to $73.3 \%$ on the average. According to the weight 
parameters Calculated using 5 coring Wells, with another 1 new coring well 5598 as testing well, $\mathrm{P}$ is calculated. The thickness of fracture development of this well is $12.6 \mathrm{~m}$. The RTC recognition rate is $42.4 \%$, and the RP recognition rate is $7.2 \%$. The fracture development thickness predicted using comprehensive probability density $\mathrm{P}$ is $9.5 \mathrm{~m}$, and the recognition rate is 75.2 (Table 1 and Fig. 8). For example, there are 4 fractured intervals at 3084.5-3085.5 m, 3086.2-3087.2 m, 3090-3091 m and 3092$3093.5 \mathrm{~m}$, respectively, in the cored interval from $3084.5-3098 \mathrm{~m}$ in Well CT-4. The fracture density is $38,12,13$ and $28 / \mathrm{m}$, respectively. These observations basically answer to the P-based results.
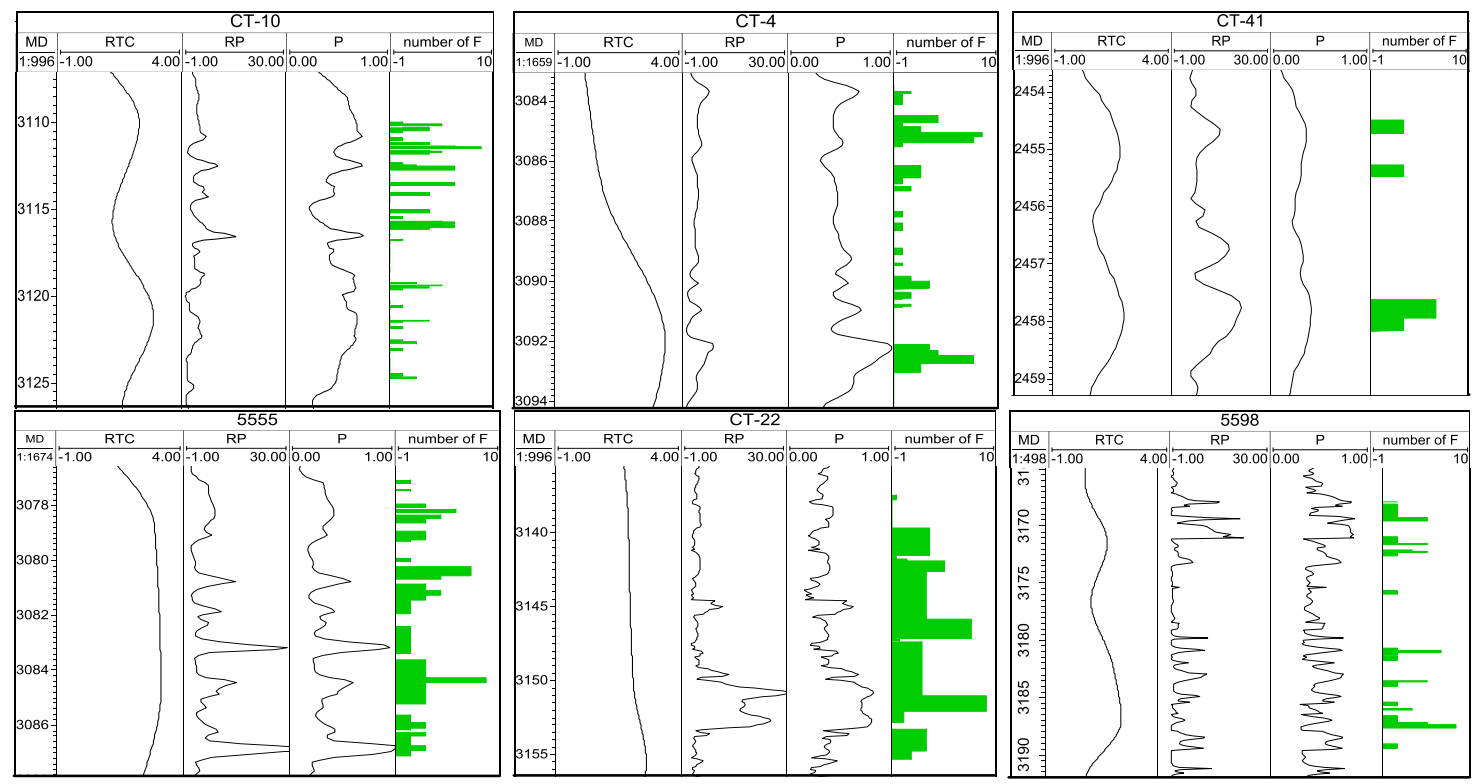

Figure 8. Fracture predictions and core observations

\section{Discussion}

Lateral and vertical distributions of fractures (Figs. 9 and 11) were delineated by the probability density calculated above. These maps and sections show that fracture distribution is related to sedimentation, karstification and tectonic movements (Braissant, 2003; Zhang et al., 2004).

Laterally more fractures occur at the structural high of the anticline, where there are 3-4 zones rich in fractures. In lower 5 and B layers, the appearance of more fractures at the structural high is attributed to large tectonic stress, where the probability density of fracture is high. The appearance of more fractures at the structural high in the upper layer A is related to two factors. One is large tectonic stress which gave rise to structural fractures. The other is the leaching process which was caused by the uplifting before the Permian Period and resulted in dissolved fractures at the structural high. Early fractures were also enlarged by the chemical erosion of atmospheric water. Thus both structural fractures and dissolved fractures occur at the structural high of the anticline in layer A.

In the intervals with shale content of $4 \%-6 \%$ and gypsum content of 0 in B2, the probability density of fracture is related to structural location. For the same lithofacies, the structural high tends to exhibit more fractures than the structural low (Andrea et al., 2016) (Fig. 10). 


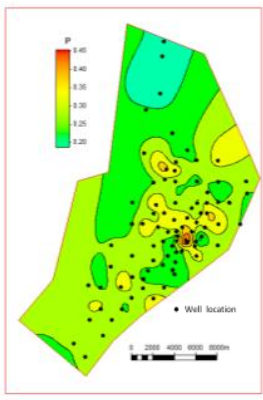

A2

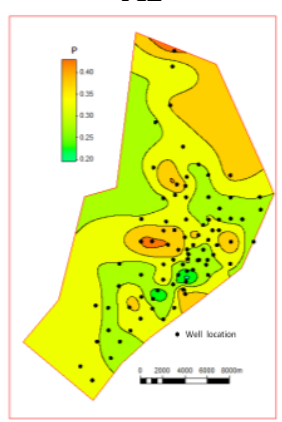

B1

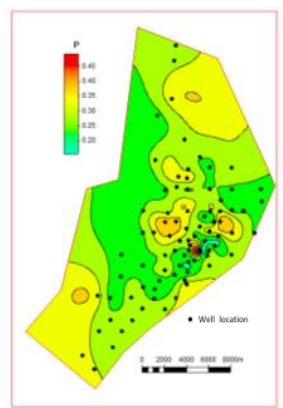

A3

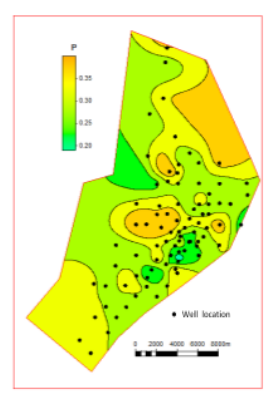

B2

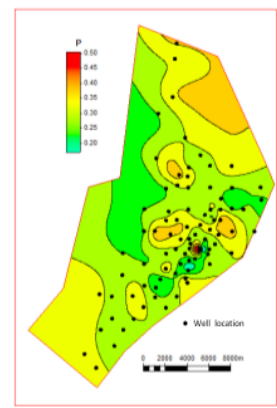

Б1

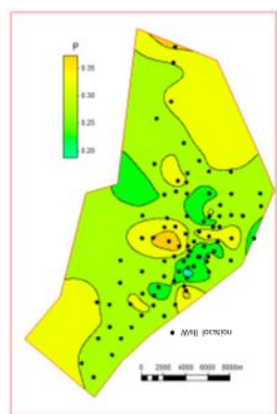

B3

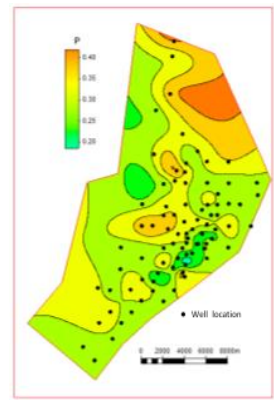

Б2

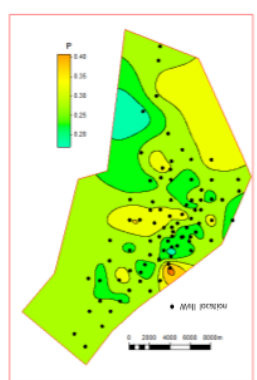

B4

Figure 9. $P$ contour maps for layers

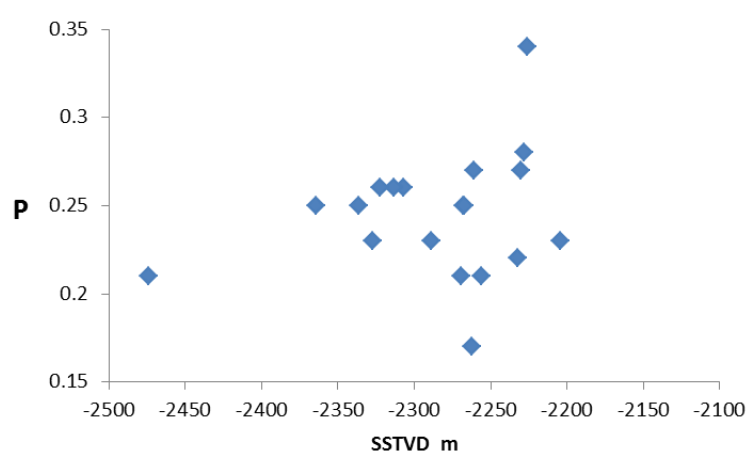

Figure 10. Fracture probability density vs. structural location. (P: the comprehensive probability density; SSTVD: subsea true vertical depth)

Vertically the appearance of fractures is dominated by sedimentary environment and varies with lithofacies. In lower B3-B5 with high shale content, fractures tend to occur in the intervals with high calcareous content instead of the ductile intervals with plastic deformation under tectonic stress (Lander and Laubach, 2015; Olson et al., 2009; Mauro et al., 2013). The probability density of fracture is only 0.21 on the average in this layer. In middle 51-B2 with minute shale content, limestone and dolomitic limestone tend to break under tectonic stress to form structural fractures; thus the probability density of fracture is 0.069-1 with an average of 0.32. In upper A with shallow water and high shale content, the evaporate platform with gypsum rocks has strong plasticity. Except local fractures at the structural high, other areas are less fractured. The probability density of fracture is 0.28 on the average. Layers A and B3-B5 at the bottom have similar shale content. But due to the effect of the leaching process, layer A has more 
dissolved fractures than B3-B5 (Table 2 and Fig. 11). Generally the probability density of fracture is negatively correlated with shale and gypsum contents and positively correlated with calcareous (calcite) content. The dolomite in the study area is mainly powder crystalline dolomite. A reservoir rock with high dolomite content is usually less fractured due to its high porosity and consequent small brittleness. Thus the appearance of fractures is negatively correlated with dolomite content (Fig. 12).

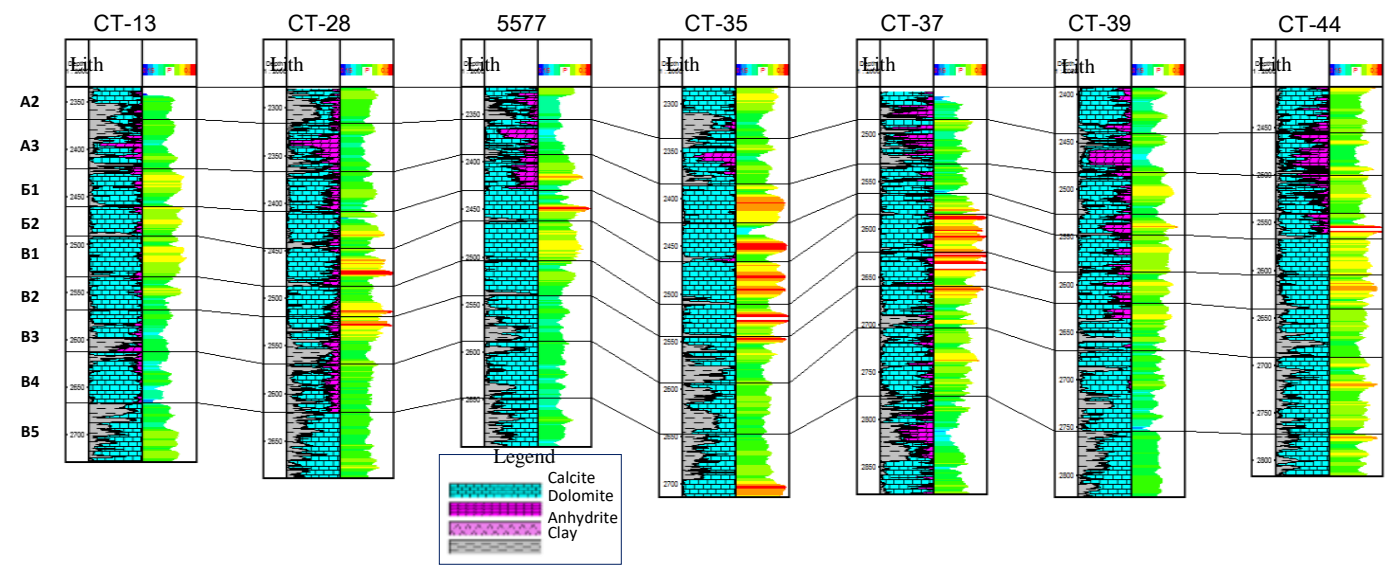

Figure 11. Vertical fracture probability density and lithologies

Table 2. Lithologies and fracture signatures in layers

\begin{tabular}{c|c|c|c|c|c|c|c}
\hline Layer & $\begin{array}{c}\text { Sedimentary } \\
\text { environment }\end{array}$ & Lithology & $\begin{array}{c}\text { Shale } \\
\text { content } \\
(\mathbf{\%})\end{array}$ & $\begin{array}{c}\text { Dolomite } \\
\text { content } \\
\mathbf{( \% )}\end{array}$ & $\begin{array}{c}\text { Calcite } \\
\text { content } \\
\mathbf{( \% )}\end{array}$ & $\begin{array}{c}\text { Anhydrite } \\
\text { content } \\
\mathbf{( \% )}\end{array}$ & P \\
\hline A & $\begin{array}{c}\text { Restricted } \\
\text { platform - } \\
\text { evaporate } \\
\text { platform, } \\
\text { shallow water }\end{array}$ & $\begin{array}{c}\text { Dolostone, limy dolostone, } \\
\text { gypseousdolostone, gypsum } \\
\text { rocks, dolomitic limestone and } \\
\text { limestone }\end{array}$ & 15.7 & 24.0 & 55.4 & 5.0 & 0.28 \\
\hline 51-B2 & $\begin{array}{c}\text { Open platform } \\
\text { restricted } \\
\text { platform, } \\
\text { shallow water }\end{array}$ & $\begin{array}{c}\text { Limestone, dolomite-bearing } \\
\text { limestone, dolomitic limestone } \\
\text { and limy dolostone }\end{array}$ & 7.0 & 10.6 & 82.3 & 0.0 & 0.32 \\
\hline B3-B5 & $\begin{array}{c}\text { Open platform, } \\
\text { deep water }\end{array}$ & $\begin{array}{c}\text { Argillaceous limestone, shale- } \\
\text { bearing limestone and limy } \\
\text { mudstone }\end{array}$ & 19.9 & 10.7 & 69.4 & 0.0 & 0.21 \\
\hline
\end{tabular}
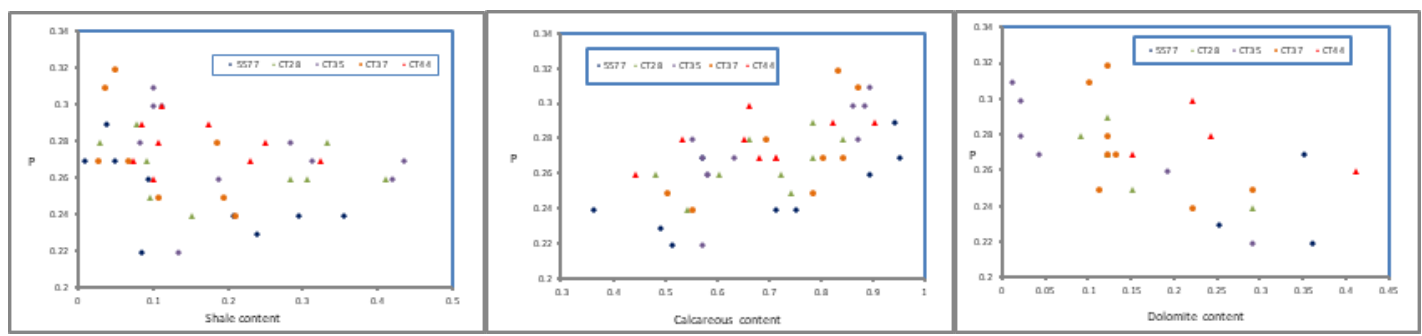

Figure 12. Fracture probability density vs. rock composition 


\section{Conclusions}

Due to the impacts of sedimentary environment, karstification and tectonic movements, the North Truwa oilfield at the east margin of the Pre-Caspian Basin has various low-angle, high-angle and net-shaped structural fractures, dissolved fractures and sutured fractures. By using a single method, i.e. resistivity difference-ratio or 3porosity ratio, only $55 \%$ of fractures on the average were identified. The fracture probability density method which integrates above two methods improves the accuracy to $73.6 \%$. The results show fracture distribution in this area is related to sedimentation, structure and diagenesis. Laterally dominated by structures and karstification, more fractures may occur at the structural high. Vertically dominated by lithofacies, more fractures occur in the brittle intervals with small shale and gypsum contents.

The purpose of carbonate reservoir fractures studing is to improve the of oil fields, so how and how much the fracture effect the production is strongly recommended to study in the future.

Acknowledgements. This study was supported by the National Major Science and Technology Project (2017ZX05030-002).

\section{REFERENCES}

[1] Ameen, M. S., Macpherson, K., Al-Marhoon, M. I. (2012): Diverse fracture properties and their impact on performance in conventional and tight-gas reservoirs, Saudi Arabia: The Unayzah, South Haradh case study. - AAPG Bulletin 96(3): 459-492.

[2] Anders, M. H., Laubach, S. E., Scholz, C. H. (2014): Microfractures: a review. - Journal of Structural Geology 69(Part B): 377-394. DOI: 10.1016/j.jsg.2014.05.011.

[3] Andrea, R., Stefano, T., Emanuele, T. (2016): Fracture characteristics in Cretaceous platform and overlying ramp carbonates: An outcrop study from Maiella Mountain (central Italy). - Marine and Petroleum Geology 76: 68-87.

[4] Babadagli, T., Al-Salmi, S. (2004): A review of permeability-prediction methods for carbonate reservoirs using well-log data. - SPE Reservoir Evalutaion \& Engineering7(2): 75-88.

[5] Bian, D. Z., Zhao, L., Chen, Y. F. (2011): Fracture characteristics and genetic mechanism of overpressure carbonate reservoirs: Taking the Kenjiyak Oilfield in Kazakhstan as an example. - Petroleum Exploration and Development 38(4): 394-399.

[6] Braissant, O., Cailleau, G., Dupraz, C. (2003): Bacteriallyinducedmineralization of calcium carbonate in teirestrialenvironments: therole of exopolysaccharides and amino acids. - International Journal of Sediment Research 73(3): 485-490.

[7] Cai, Z. Q., Qin, Q. R., Liu, Q. M. (2003): Integrate prediction of fractured reservoir with carbonate rock in Changxing Group in mid-south section of Tongluoxia Structure. - Acta Petrolei Sinica 24(3): 42-45.

[8] Dong, S. B., Ke, S. Z., Zhang, H. J. (2013): On fracture identification with conventional well logging data. - Well Logging Technology 37(4): 380-388.

[9] Gong, H. L., Pan, J. G., Wang, H. B. (2007): Comprehensive fracture prediction technologies and their application to carbonate rocks in Tazhong area. - Oil \& Gas Geology 28(6): 841-846.

[10] He, L., Zhao, L., Li, J. X. (2014): Complex relationship between porosity and permeability of carbonate reservoirs and its controlling factors: A case of platform facies in Pre-Caspian Basin. - Petroleum Exploration and Development 41(2): 206-214. 
[11] Kazatchenko, E., Markov, M., Mousatov, A. (2007): Joint inversion of conventional well $\operatorname{logs}$ for evaluation of double-porosity carbonate formations. - Journal of Petroleum Science and Engineering 56(4): 252-266.

[12] Lai, J., Wang, G., Fan, Z. (2017): Fracture detection in oil-based drilling mud using a combination of borehole image and sonic logs. - Marine and Petroleum Geology 84: 195214.

[13] Lander, R. H., Laubach, S. E. (2015): Insights into rates of fracture growth and sealing from a model for quartz cementation in fractured sandstones. - Geological Society of America Bulletin 127(3-4): 516-538.

[14] Li, N. (2013): Introduction to logging interpretation of China marine carbonate rocks. Science Press.

[15] Luo, L., Hu, P. Y., Zhou, Z. Y. (2001): Log identification for fracture in carbonate. Acta Petrolei Sinica 22(3): 32-35.

[16] Mauro, C., Guido, B., Norihiro, W. (2013): Modelling of fractured carbonate reservoirs: outline of a novel technique via a case study from the Molasse Basin, southern Bavaria, Germany. - Environmental Earth Sciences 70(8): 3585-3602.

[17] Olson, J. E., Laubach, S. E., Lander, R. H. (2009): Natural fracture characterization in tight-gas sandstones: Integrating mechanics and diagenesis. - AAPG Bulletin 93: 15351549.

[18] Sibbit A. M., Faivre, O. (1985): The Dual Laterlog Response in Fractured Rocks. SPWLA 26th Annual Logging Symposium, Dallas, Texas, SPWLA-1985-T.

[19] Sima, L. Q., Shu, Z. Z. (2009): Well Logging Evaluation Techniques and Application to Carbonate Reservoirs. - Petroleum Industry Press, Beijing.

[20] Sun, J. M., Liu, R., Mei, J. X. (1999): Fracture identification technique by conventional logs from Western Chaidamu Basin, Qinghai Oilfield. - Well Logging Technology 23(4): 268-272.

[21] Tang, X. M., Zeng, L. B., Yue, F. (2012): Fracture characterization and identification by conventional logs of shale reservoirs in Ordos Basin. - Journal of Oil and Gas Technology 34(6): 95-99.

[22] Wang, S. Q., Zhao, L., Cheng, X. B. (2012): Geochemical characteristics and genetic model of dolomite reservoirs in the eastern margin of the Pre-Caspian Basin. - Petroleum Science 2: 161-169.

[23] Wang, S. Y., Li, X. G. (2006): Well Logging Evaluation Principles and Methods for Complex Reservoirs. - Petroleum Industry Press, Beijing.

[24] Yan, X. Z., Wang, Z. G., Liu, Q. J. (2009): Reservoir fracture prediction by multiparameter criteria method. - Petroleum Exploration and Development 36(6): 749-755.

[25] Zhang, X. M., Yang, J. (2004): Reservoir description and reserves estimation technique for fracture-cave type carbonate reservoir in Tahe Oilfield. - Acta Petrolei Sinica 25(1): 13-18.

[26] Zhao, L., Li, J. X., Li, K. C. (2010): Development and genetic mechanism of complex carbonate reservoir fractures: A case from the Zanarol Oilfield, Kazakhstan. - Petroleum Exploration and Development 37(3): 304-309.

[27] Zhao, L., Chen, Y. F., Ning, Z. F. (2013): Stress sensitive experiments for abnormal overpressure carbonate reservoirs: A case from the Kenkiyak low-permeability fracturedporous oilfield in the littoral Caspian Basin. - Petroleum Exploration and Development 40(2): 194-200.

[28] Zheng, X. D., Xu, A. N. (2005): Seismic Prediction of Prolific Oil Zones in Carbonate Reservoirs with Extremely Low Porosity and Permeability under Salt. - Applied Geophysics 2(2): 103-110. 